\section{Military Technical College Kobry El-Kobbah, Cairo, Egypt}

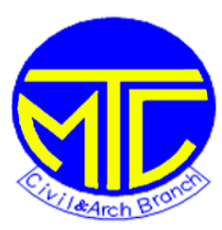

\section{$12^{\text {th }}$ International Conference on Civil and Architecture Engineering ICCAE-12-2018}

\title{
Finite Element Simulation of Space Trusses
}

\author{
B. Eltaly ${ }^{\mathrm{a}}$, M .Nawar ${ }^{\mathrm{b}}$ and K. Kandeel ${ }^{\mathrm{c}}$ \\ ${ }^{a}$ Associate Professor, Civil Engineering Department, Faculty of Engineering, Minoufia University, Egypt. \\ ${ }^{\mathrm{b}}$ MSc student, Civil Engineering Department, Faculty of Engineering, Minoufia University, Egypt. \\ ${ }^{c}$ Professor, Civil Engineering Department, Faculty of Engineering, Minoufia University, Egypt.
}

\begin{abstract}
The purpose of this paper is introducing a simplified and computationally efficient finite element model to investigate the nonlinear behavior of composite and non-composite space trusses. Two models were employed using the Finite Element ANSYS program in order to analyze the space trusses. The first model simulates the non-composite space trusses while the second model simulates the composite space trusses. Also this research presents the comparisons between the results of the current finite element models and four previous published space trusses in order to verify the validity of the current models. Comparisons between the results of the two models and the results of the four previous published space trusses indicated that the numerical analysis created by the FE ANSYS program using the two employed models can predict the general collapse behavior of the space trusses.
\end{abstract}

Keywords: Space trusses; Double layer grids; MERO connection; Composite space truss; Nonlinear analysis

\section{Introduction}

Space truss systems became a common usage in the mid-nineteenth century and it is considered a good structural system to cover large open areas with few or no internal supports. The growing popularity of space truss is due to a number of distinct advantages. These advantages are the ability, light weight, easy of assembly, presence of empty spaces between members which can be used to accommodate services and the great rigidity that leads to relatively small deflections (high stiffness/weight ratio). There are several successful space truss applications now exist all over the world covering stadium, public halls, exhibition centers, airplane hangars, and many other buildings. Space trusses are made from different materials such as steel, aluminum, wood...etc. They comprise set of members that are assembled to give different shapes such as flat system, curved system, spherical system and linear system. The available space trusses were classified into two main groups according to their connection system. The first is the system with short chord members (typical space truss). In this system, the truss members joined together by node connectors; MERO and Triodetic connections as examples. The second is the system with continuous chord members. This system does not need nodes for their assembly. The most adopted connection used in these systems is the nodes stacked end-flattened bars connected by a single large diameter bolt. This type of joint is simple and therefore cheaper to manufacture. However, it has two main disadvantages: the generated eccentricity force and a reduction of stiffness in the bar due to the end-flattening process [1-10].

From the time of the sudden collapse of Hartford Coliseum space truss in Connecticut in 1978 occurred because of the buckling of their compression members, a large number of theoretical and experimental research programs were done to study the nonlinear behavior of these 
structures at different institutes. Schmidt et al. [11] investigated a theoretical model for the tested trusses. In their model, the strut theoretically behaves as a brittle member. There may be no reserve of the strength beyond the initial buckling of the strut; a sharp drop in load capacity may be expected immediately after the initial buckling. Schmidt and Gregg [12] presented a method to analyze space trusses in the post-buckling range. The method used piecewise linearization of the strut behavior. Same technique was used by other researchers such as Smith [13], Smith and Smith [14] and Supple and Collins [15]. In all of these researches, the member was not removed when it reached its buckling strength. Their programs were designed to allow changing the stiffness of the member whose forces reached to its bucking or yielding value. They concluded that these methods gave excellent correlation with modeling several characteristics of experimental results.

Blandford [16] used constitutive relationships to provide the fundamental modeling of elastic and inelastic behavior of the space truss member coupled with a geometrically nonlinear finite element model. Yang et al. [17] proposed an incremental analysis procedure based on an accurate updated Lagrangian formulation for analyzing the post buckling behavior of the space trusses. They concluded accurate solutions in comparing with the experimental work. Greco et al. [18] proposed a formulation used nodal positions to describe the behavior of the space truss. Their results concluded that the proposed formulation gives accurate responses compared with analytical and other numerical solutions. Aboul-Anen et al. [19-20] and Eltaly [21] presented three new models using the finite element program (ANSYS) in order to study the nonlinear behavior of the space trusses. Link8 and Combined39 were the two elements which used to create the new models. Their results indicated that there is a good agreement between results of these models and the published experimental and numerical results especially in the elastic zone.

Substantial works have been reported on methods of improving space truss behavior. Schmidt and Honaor [22] and EL-Sheikh [23] introduced an artificial ductility to compression member by building into it a Force Limiting Device (FLD). FLD is a device used to make the member yielding under a fixed predetermined force and would maintain this force under increasing the deflection. Also over-strengthening top chord members or using top slab acting compositely with the top chord improves the overall behavior of space trusses. By over-strengthening top chord members or using concrete slab acting compositely with the top chord, the buckling problems of the compression cord members are reduced. Over-strengthening top chord members increase the ductility of the truss. Adding top slab improves joint stability and truss reliability. Also it leads to significant enhancements to truss stiffness, strength and ductility. This approach also leads to improvements in truss response to member loss and uneven support settlements (Eltaly [21], ElSheikh [24-25] El-Sheikh and McConnel [26] and EL-Sheikh and Shaaban [27]).

The main objective of this paper is to introduce and discuss nonlinear finite element models to simulate the behaviour of composite and non-composite space trusses up to failure. ANYSY package was used to build these models. Several numerical examples were presented to demonstrate the ability of the present models.

\section{FE Simulation}

Two FE models (Model\#1 and Model\#2) were employed in order to analyze the space trusses. Model\#1 simulates the non-composite space trusses and Model\#2 simulates the composite space trusses. 
In model\#1, all truss members were modeled by Link180 element. Link180 element is 3-D spar element that can be used in a variety of engineering applications; truss and sagging cables as example. This element is a uniaxial tension-compression element with three degrees of freedom at each node: translation in the nodal $\mathrm{x}, \mathrm{y}$ and $\mathrm{z}$ directions. As a pin-jointed structure, no bending of the element is considered. Plasticity, creep, rotation, large deflection, and large strain capabilities can be considered. Elasticity, creep, isotropic hardening plasticity and kinematic hardening plasticity are supported [28].

Model\#2 is similar to model\#1 except the simulation of the top members and the top slab. The top members were modeled by Pipe 20 element while the element used to simulate the top slab depends on the material and the shape of the slab. Top members in composite trusses are subjected to the bending moment and work with top slab in composite action, therefore the Pipe20 element was used to simulate the top members instead of Link180 elements. Pipe20 element is a uniaxial element with tension-compression, bending and torsion capabilities. The element has six degrees of freedom at each node: translations in the nodal $\mathrm{x}, \mathrm{y}$ and $\mathrm{z}$ directions and rotations about the nodal $\mathrm{x}, \mathrm{y}$ and $\mathrm{z}$ axes. The element has plastic, creep and swelling capabilities. The element input data include two nodes, the pipe outer diameter and the wall thickness, optional stress factors and the isotropic material properties [28].

The material in the two models was defined to the FE program ANSYS according to the behavior of the individual members and the classification of the truss members. The members were classified according to the type of the internal force for each member, tension force or compression force. To indicate compressive and tensile members, linear analysis of the studied trusses was performed using SAP2000N program [29]. The current model considered the material nonlinearity in the analysis of the truss. The material nonlinearity was represented by selecting Multi-linear Kinematic Hardening (MKIN) technique. All members were modeled as elastic-plastic material where the material defined by ANSYS in two parts; the first part is linear elastic material model and the required values are the elastic modulus $\left(\mathrm{E}_{\mathrm{s}}\right)$ and Poisson's ratio (v) while the second part is multi-linear inelastic to represent the stress-strain behavior of the material obtained from the test of the individual members under tensile and compressive force. The non-linear analysis was carried out using the displacement-control technique. In this technique, the displacement is divided into a series of increments called load displacement steps.

\section{Studied Space Trusses}

This section presents the nonlinear behavior of four different space trusses using the employed FE models. The four space trusses were previously studied analytically and experimentally and their results were published in various institutes.

\section{1. $\quad$ Studied Space Truss (1)}

Schmidt et al. [11] had studied experimentally and theoretically the post collapse behavior of three models of space trusses in square on square form. Each truss model has $1830 \times 1830 \mathrm{~mm}$ overall dimensions and $216 \mathrm{~mm}$ depth. The three models were fabricated from the aluminum tubes with $12 \mathrm{~mm}$ external diameter and $1.5 \mathrm{~mm}$ wall thickness. The members were collected at the joints using triodetic connection system. The models were supported at each lower chord perimeter joint and loaded at four symmetrically joints. Fig. 1 shows the overall view of the truss. A set of tests were carried out on the individual members that form the trusses by Schmidt et al. [11] to obtain the behavior of the compression and the tension members and their results are presented in 
Fig. 2. From the stress-strain curve, modulus of elasticity and Poisson's ratio of the trusses were considered as $43.5 \mathrm{GPa}$ and 0.25 , respectively.
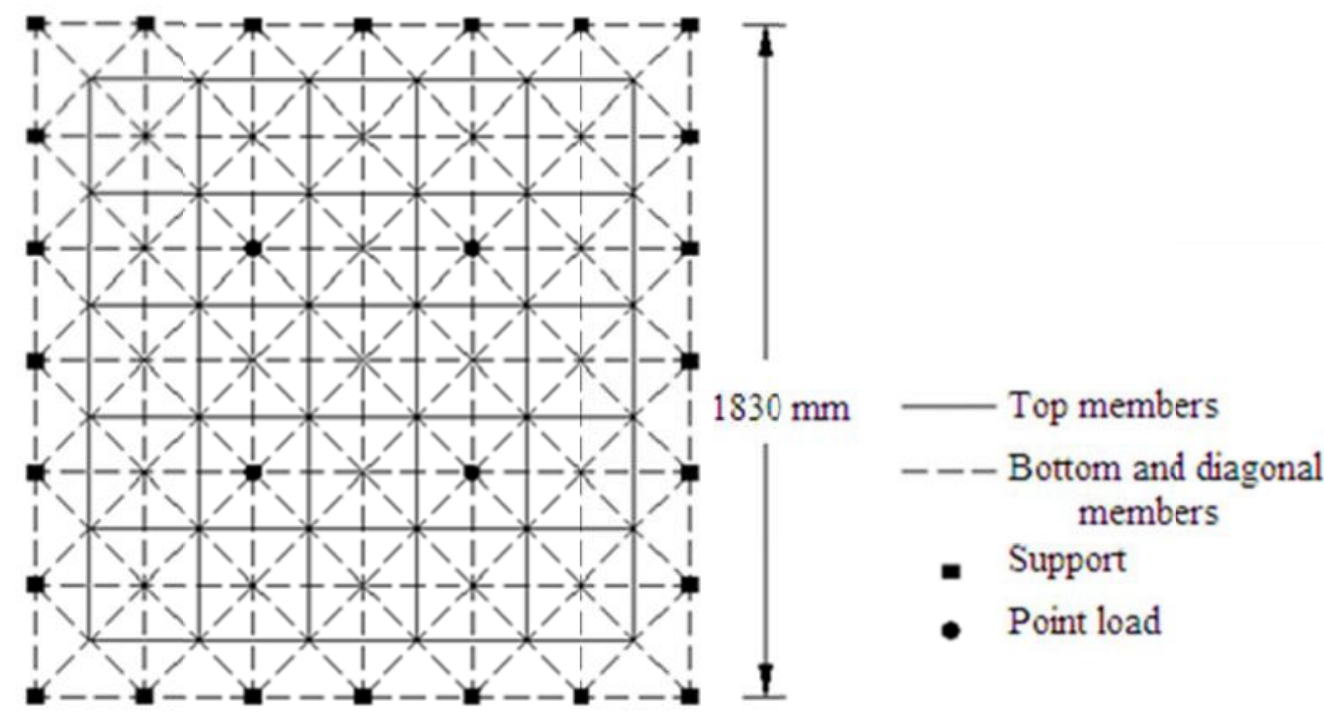

Fig. 1. Geometry of Schmidt et al. [11] Space Truss

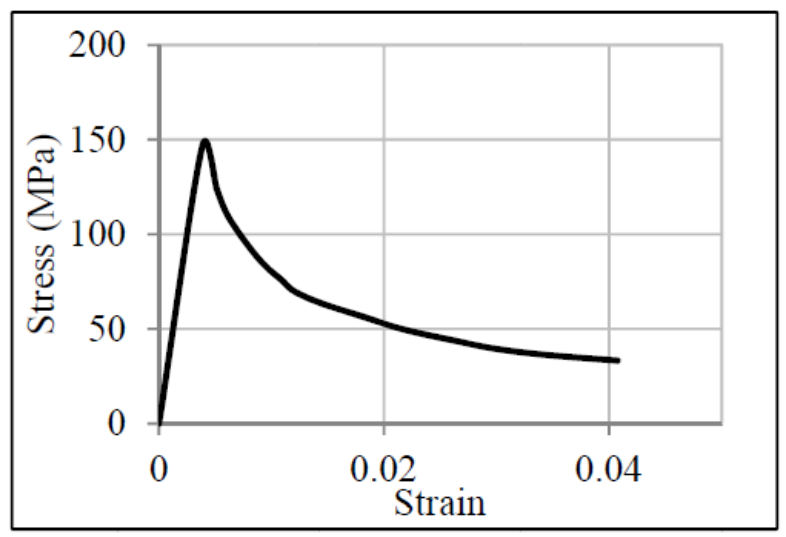

a) Compressive test

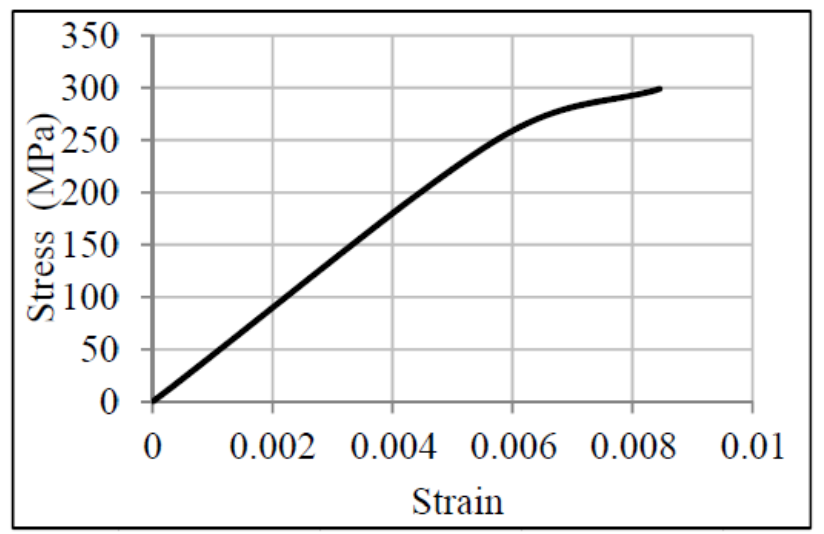

b) Tensile behavior

Fig. 2. Behavior of the individual members of the studied space truss (1)

Fig. 3 shows the relationship between the applied load and the central deflection as recorded from Schmidt et al. [11] experimental tests and theoretical analysis and the current FE analysis using model\#1. From this figure, it can be concluded that the analysis carried out by Schmidt et al. [11] predicted the load at the end of the linear stage was greater than their experimental results by $27 \%$. Schmidt assembly process, non-symmetrical strain distribution within the structure in the elastic range and the imperfections inherent in the compression members were the factors that led to the difference in their experimental and theoretical results. From Fig. 3, it can be seen that a good agreement between the experimental results and the current results with a 
slight difference does not exceed than $4 \%$ in the linear and the nonlinear stage. The sequences of collapsed members obtained from experimental work and current analysis using model\#1 were shown in Fig. 4. This figure indicates a symmetric pattern of collapse from the current model. Also the figure shows an un-symmetric pattern of collapse from the experimental work by Schmidt et al. [11]. It should be noted that Schmidt et al. [11] concluded that the un-symmetric pattern of collapse in the truss members might be accrued due to the variability of the memberhub interaction within the truss.

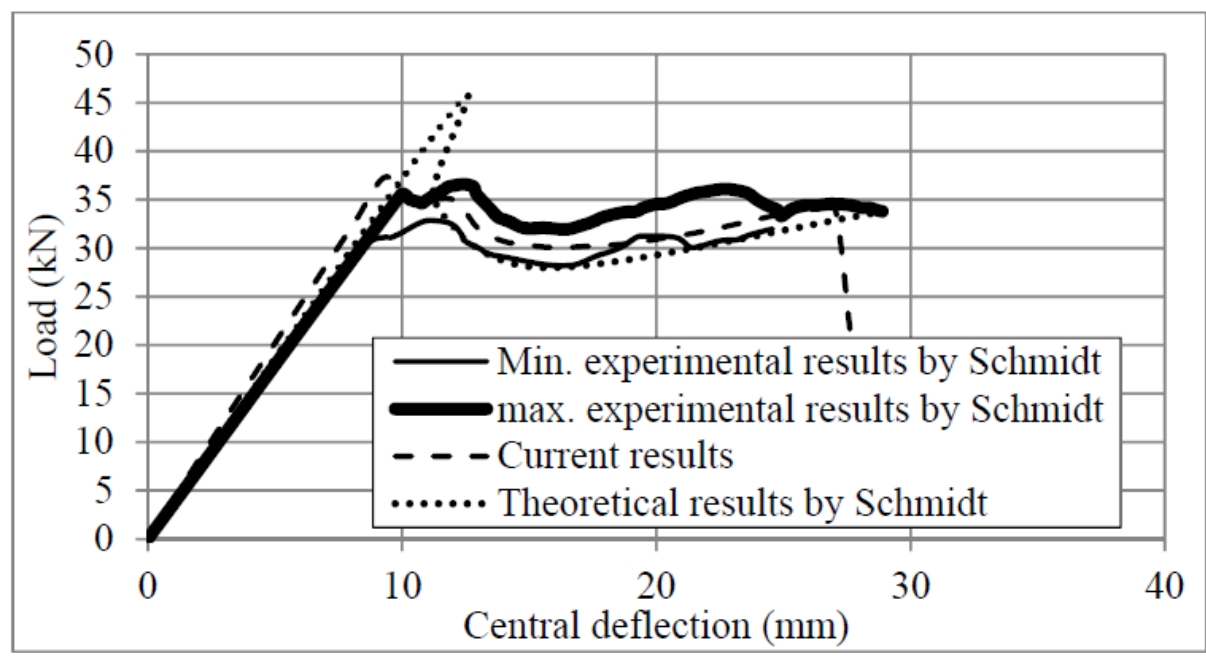

Fig. 3. Load - central deflection curve of the studied space truss (1)

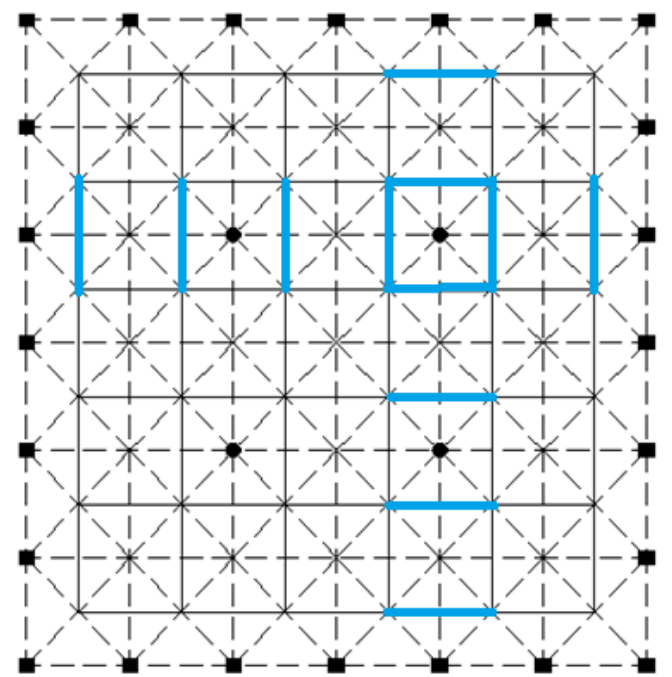

Collapsed members

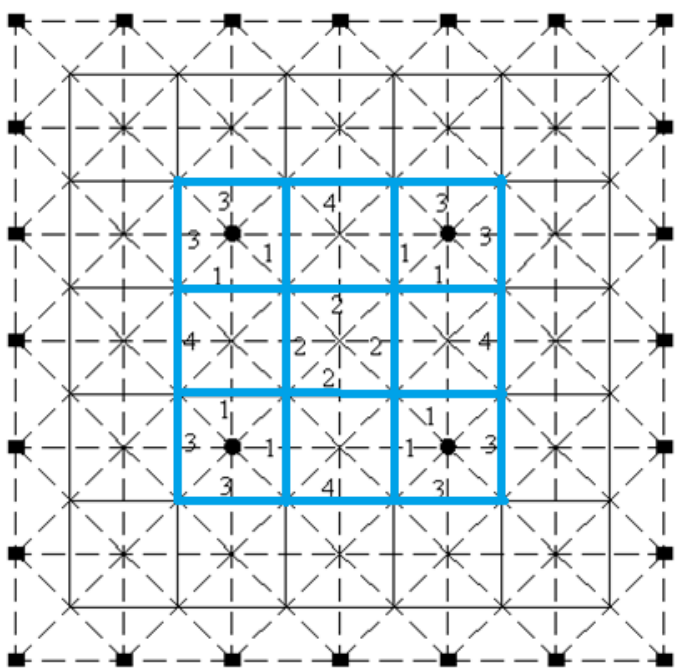

b) Analytical analysis

a) Experimental work [11]

Fig. 4. Sequence of the collapsed members of the studied space truss (1)

\section{2. $\quad$ Studied Space Truss (2)}

Collin [30] studied experimentally the collapse behavior of four models of double - layer grids space truss. The four models have $1800 \times 1800 \times 254.56 \mathrm{~mm}$ overall dimension as shown in Fig. 5. All members of the four models were made from mild steel tube with $9.52 \mathrm{~mm}$ external diameter and $0.81 \mathrm{~mm}$ wall thickness. The trusses were supported on four corner nodes and the 
members were connected at the joints by welding. This model was loaded symmetrically about the diagonal axis (A-A) at joints 9 and 29 using the displacement -control technique. Fig. 6 shows the behavior of the individual members under compression and tension force. Modulus of elasticity, yield stress and Poisson's ratio of the truss material are considered as 203.936 GPa, 281.7 Mpa and 0.3, respectively in the current analysis.
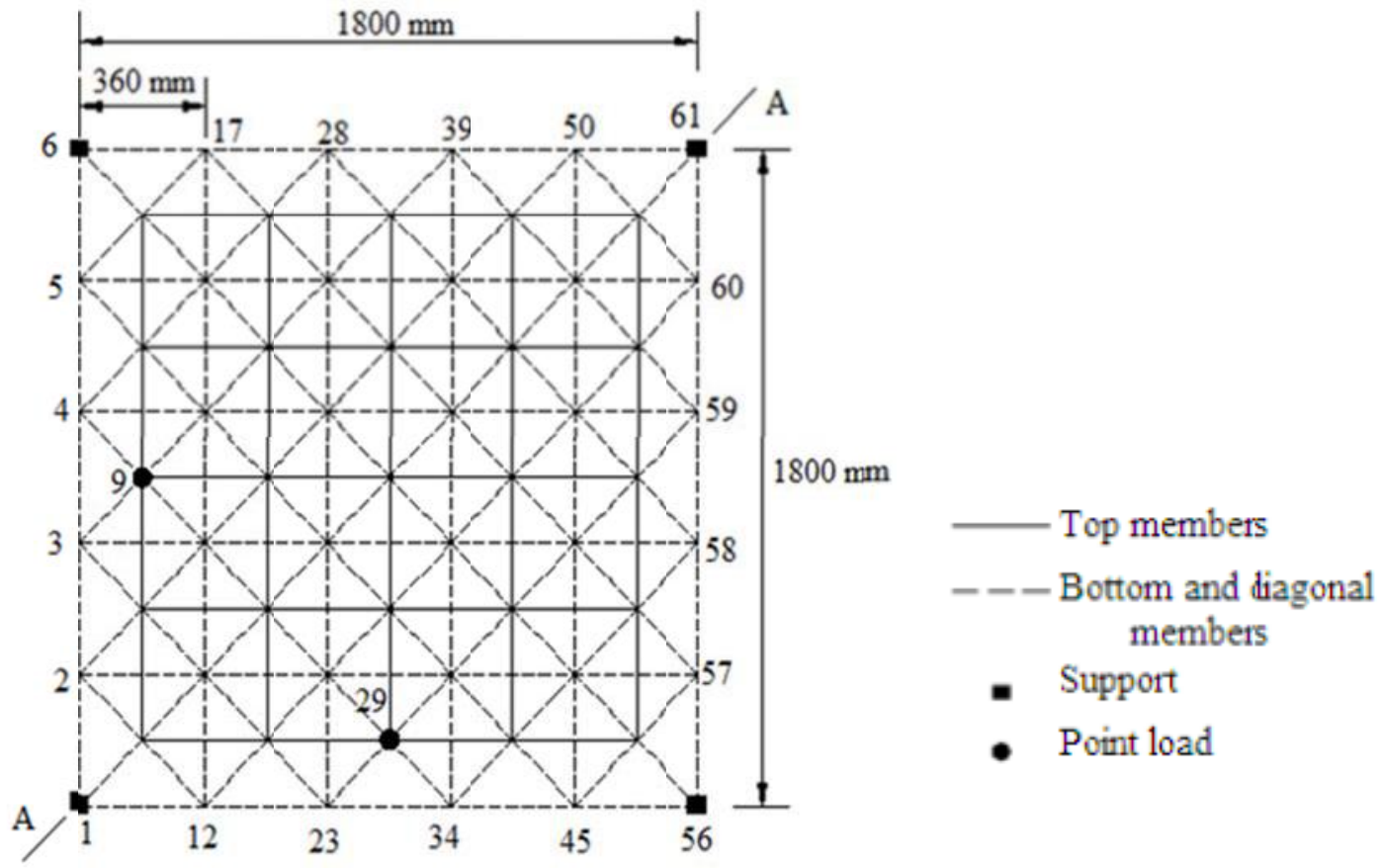

Fig. 5. Geometry of Collin's space truss

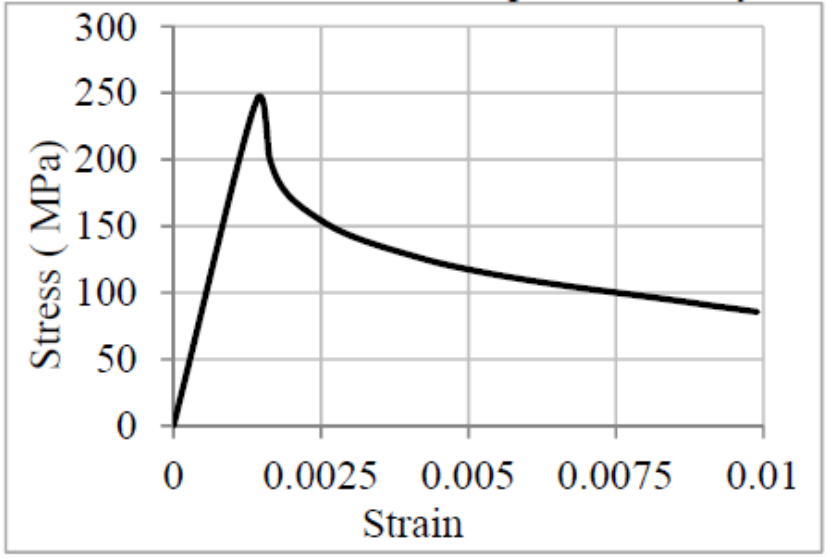

a) Compressive behavior

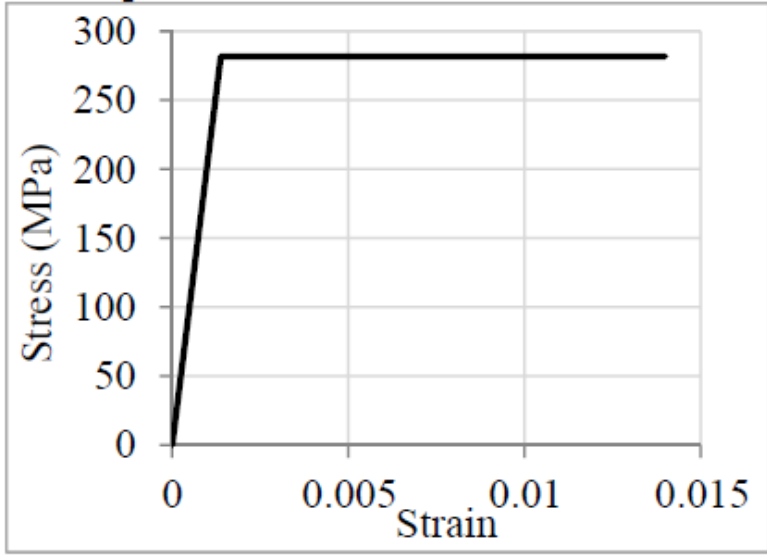

b) Tensile behavior

Fig. 6. Behavior of the individual members of the studied space truss (2)

Fig. 7 shows the relationship between the applied vertical displacement at joint 9 and 29 and the corresponding load at each node due to Collin's results and the current results. This figure indicated that the experimental relationship between load and deflection remained linear until the load of $4.233 \mathrm{kN}$ at joint 9 and $3.885 \mathrm{kN}$ at joint 29 then the relationship became nonlinear up to failure. Also this figure indicated that the current analytical results are in a good agreement in compari $\mathrm{g}$ with experimental results. 
The experimental results indicated that the members (8-9) and (18-29) were the first buckled members at the start of the nonlinear stage of the load-deflection relationship. With further increments of displacement, the members started to collapse in a symmetrical sequence about axis A-A as follow: the members (19-20) and (19-30) failed in compression then the member (34 ) in tension then the members (25-36) and (25-26) in compression. After that member (23-29) yielded then the members (31-32) and (31-42) buckled and followed by the buckling of members (20-31), (20-21), and (42-43) (see Fig. 8). The current analytical analysis indicated that members (8-9) and (18-29) were the first buckled members at displacement $3.97 \mathrm{~mm}$. Increasing displacement to reach $6.39 \mathrm{~mm}$, members (19-20) and (19-30) were buckled and followed by buckling members (25-36) and (25-26) at displacement $15.67 \mathrm{~mm}$. Also members (3-4) and (2334) collapsed in tension at displacement $33.52 \mathrm{~mm}$ (see Fig. 8). Fig. 9 shows the load-axial stress relationship due to the experimental and the analytical results for member (8-9) and member (18-29).

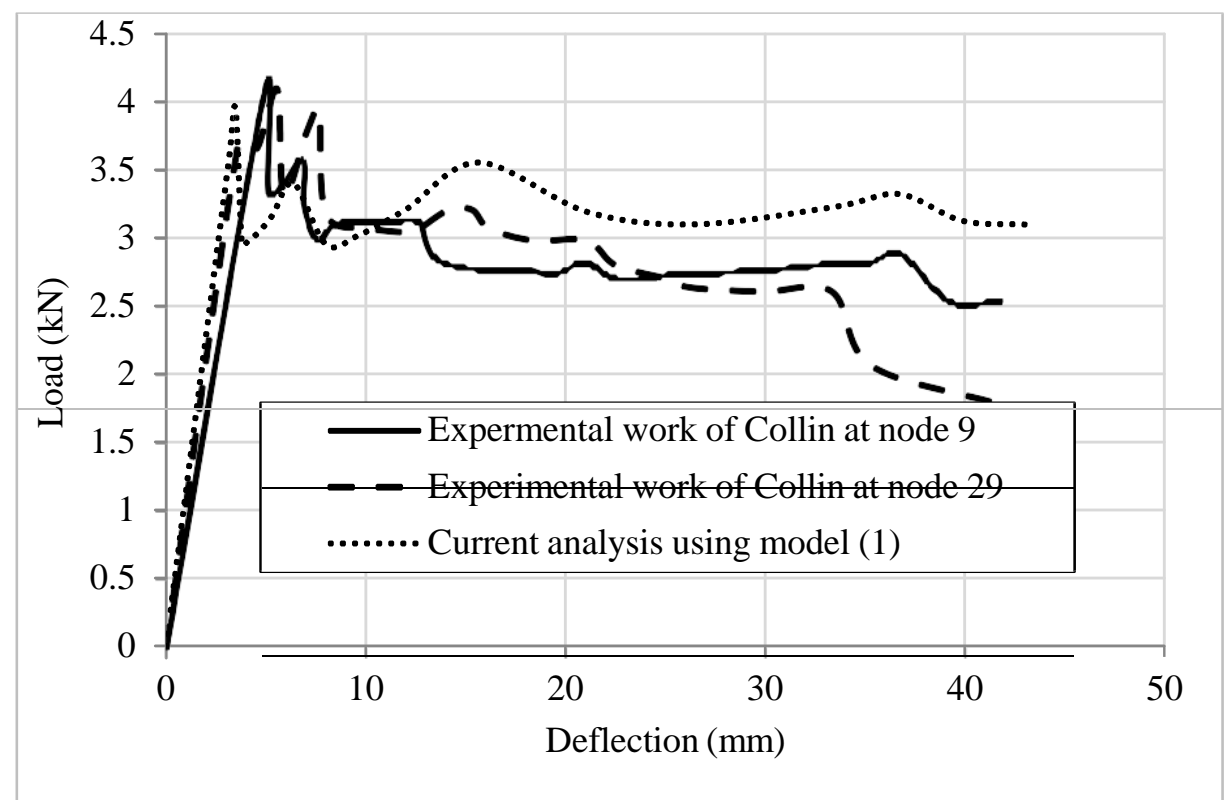

Fig. 7. Experimental and the analytical load - deflection curves for the studied space truss (2) 


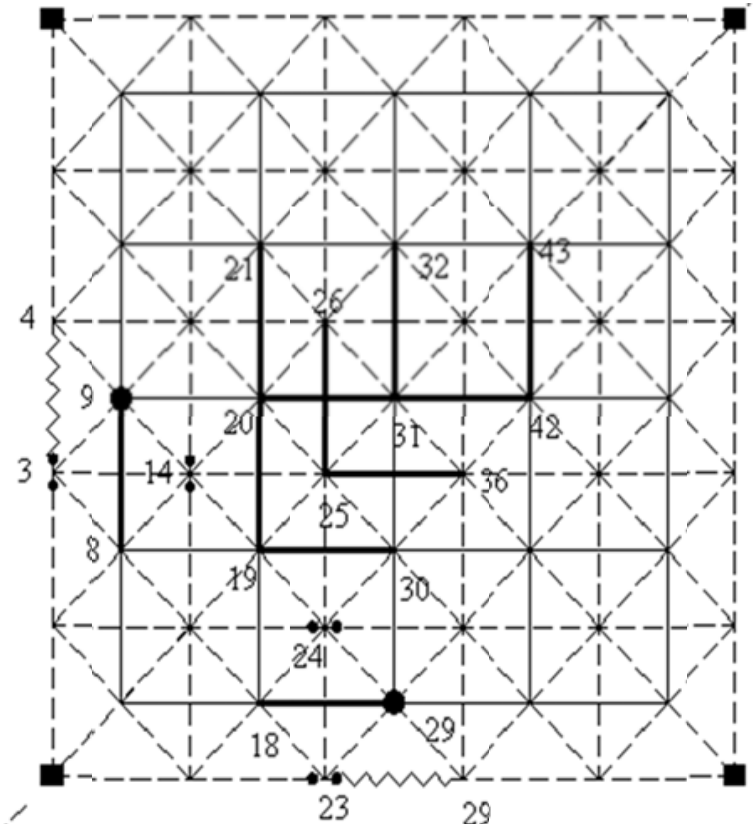

W Tensile failure

a) Experimental work

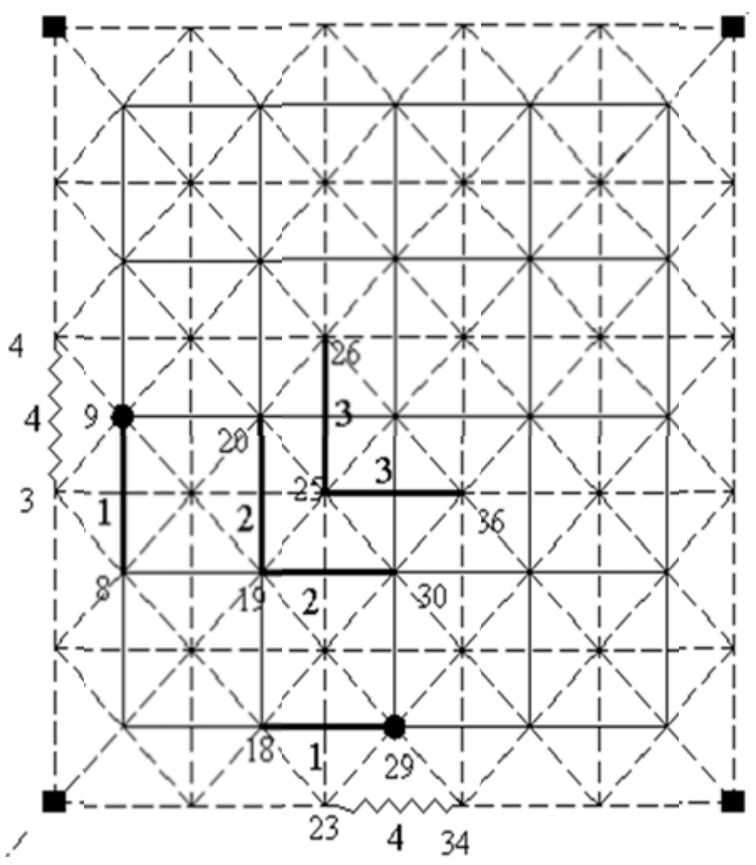

Buckling failure

b) Analytical analysis

Fig 8 Collapsed members of the studied space truss

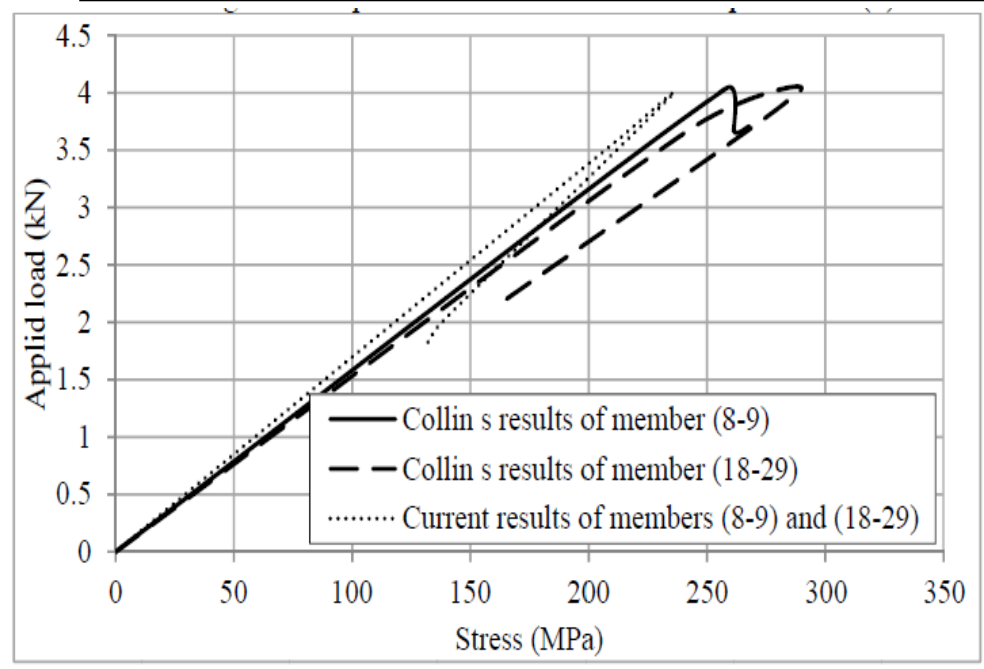

Fig. 9. Experimental and the current analytical relationship between the applied Load and the stress in studied space truss (2) members

\section{3. $\quad$ Studied Space Truss (3)}

El-Sheikh [25] studied experimentally and analytically the ability of improving the non-linear behavior of a square on square form space trusses using the composite action and overstrengthening the top chord members. He studied three space trusses. The first truss (Truss (A)) and the second truss (Truss (B)) are non-composite space trusses and the third truss (Truss (C)) is a composite space truss. All trusses were with overall dimensions $4000 \times 4000 \mathrm{~mm}$ and the depth 
of the trusses was chosen to be $575 \mathrm{~mm}$ (see Fig. 10). Truss (A) has diagonal and bottom members with tube cross section $(25.58 \mathrm{~mm}$ diameter and $1.63 \mathrm{~mm}$ thickness). Its top members are with toes-up channel sections $(40 \times 24 \times 1.6 \mathrm{~mm}$ dimensions $)$. Its four diagonal corner members had a tube section with $60.3 \mathrm{~mm}$ diameter and $3.2 \mathrm{~mm}$ thickness. Truss (B) has same sections of Truss (A) except the top members were made from toes-up channel section with $51 \times 38 \times 6.4 \mathrm{~mm}$ dimensions. Truss (C) is similar to Truss (A) but with top concrete slab of 50 $\mathrm{mm}$ thickness and $5 \varnothing 6 / \mathrm{m}$ reinforcement in each direction. Shear connectors were used to connect the concrete slab with the top members of the composite truss. The shear connectors were studs of $12 \mathrm{~mm}$ diameter and $40 \mathrm{~mm}$ length. The bottom and the diagonal members were collected at the joints using MERO connection while the end plates welded to the channels were used to bolt the top chord members directly to the upper nodes.

Three trusses were supported on the four bottom corner nodes with a span of $3200 \mathrm{~mm}$ in each direction. Truss (A) and truss (C) were designed to study the effect of adding top concrete slab on the behavior of the truss. Truss (B) was designed with over-strengthened top chord members to be alternative with the effect of the composite action. The trusses were loaded uniformly by vertical loads at sixteen points loads (see Fig. 10).

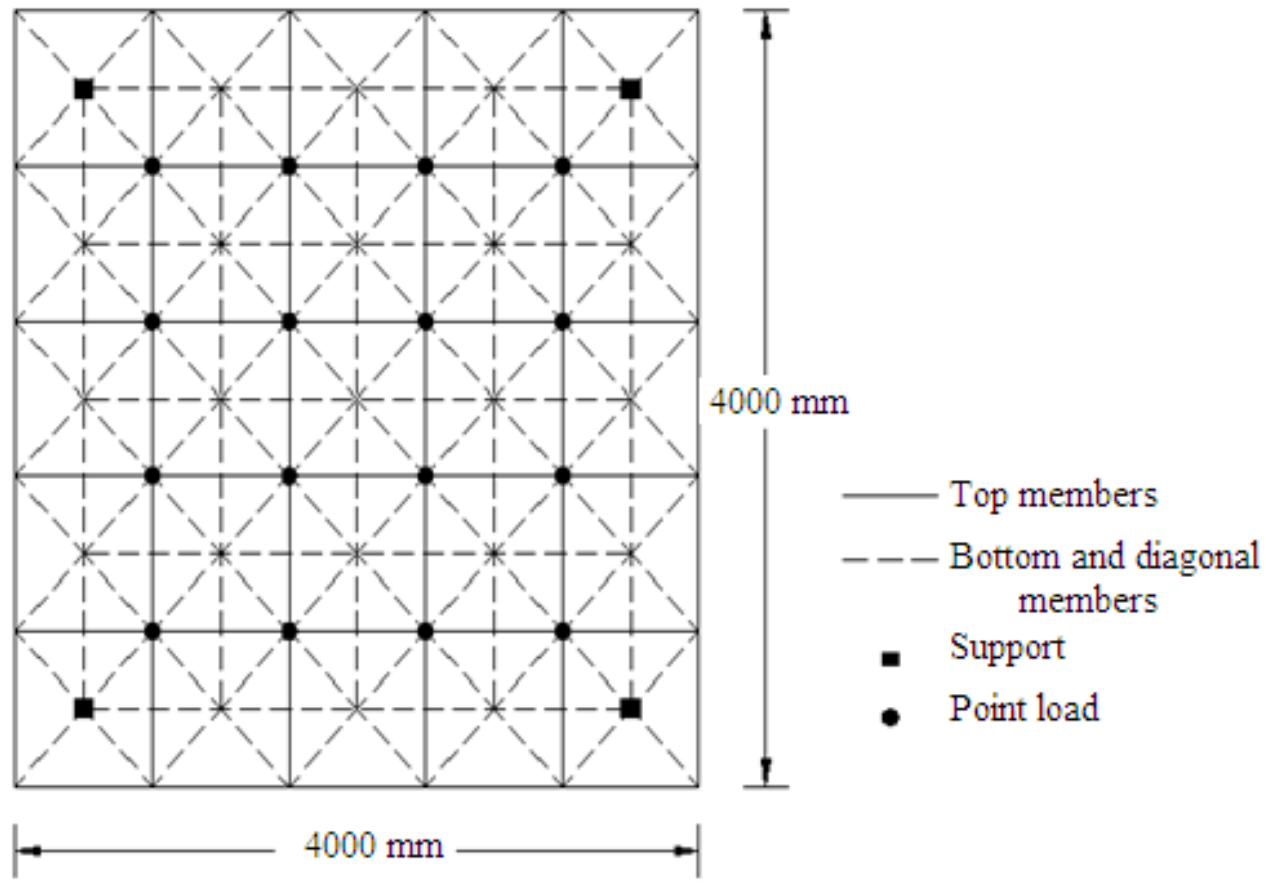

Fig. 10. Geometry of El-Sheikh's space truss

El-sheikh [25] concluded that behavior of MERO connection of space trusses lies between the hinged and the fixed ends conditions so that the compression tests were carried out on the members with fixed and hinged ends. Fig. 11 shows the behavior of the individual members under tension and behavior of the bottom and the diagonal members as examples under compression force compression test. 


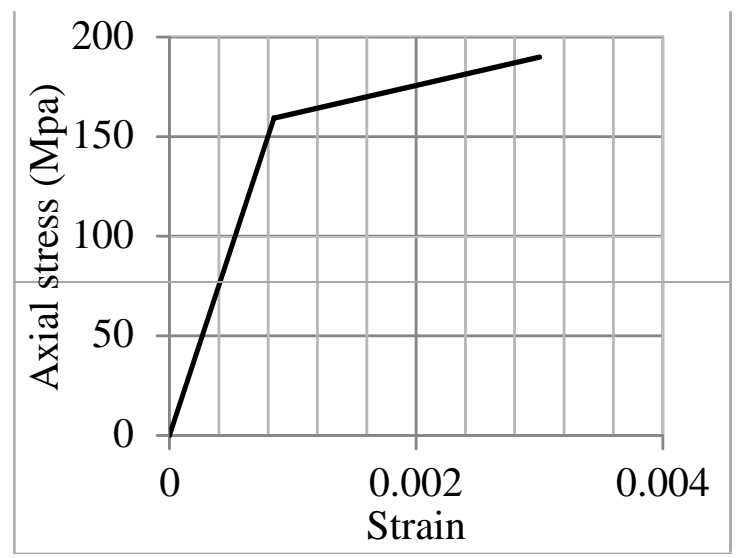

a) Tensile behavior

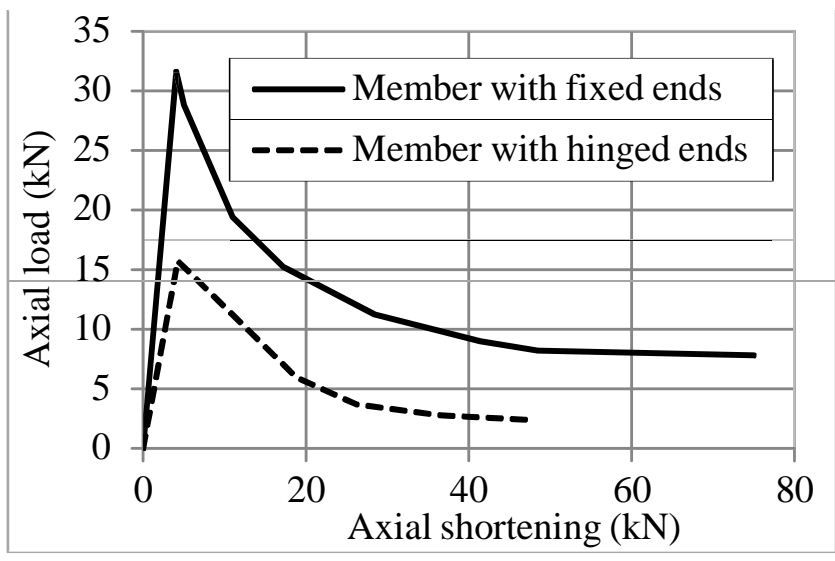

b) Compressive behavior

Fig. 11. Behavior of the individual members of the studied space truss (3)

The experimental results of Truss (A) indicated that the collapse was occurred suddenly without any warning at applied total load $100 \mathrm{kN}$. The relationship between the applied external load and deflections at central node was remained linear up to the applied total load $100 \mathrm{kN}$ as shown in Fig. 12. Analysis of truss (A) using model\#1 indicated that the analytical load - central deflection curve agrees with El-Sheikh [25] experimental results as shown in Fig. 12. The experimental results indicated that the top member (34-35) was first buckled, and then followed by buckling of members (40-41), (28-29), (46-47) and (52-53) that were buckled sequentially after five seconds (see Fig. 13). The current analysis indicated that the first buckled members were (40-41), (46-47), (41-47) and (40-46) then followed by (43-35), (52-53), (42-48) and (4945) as shown in Fig. 13.

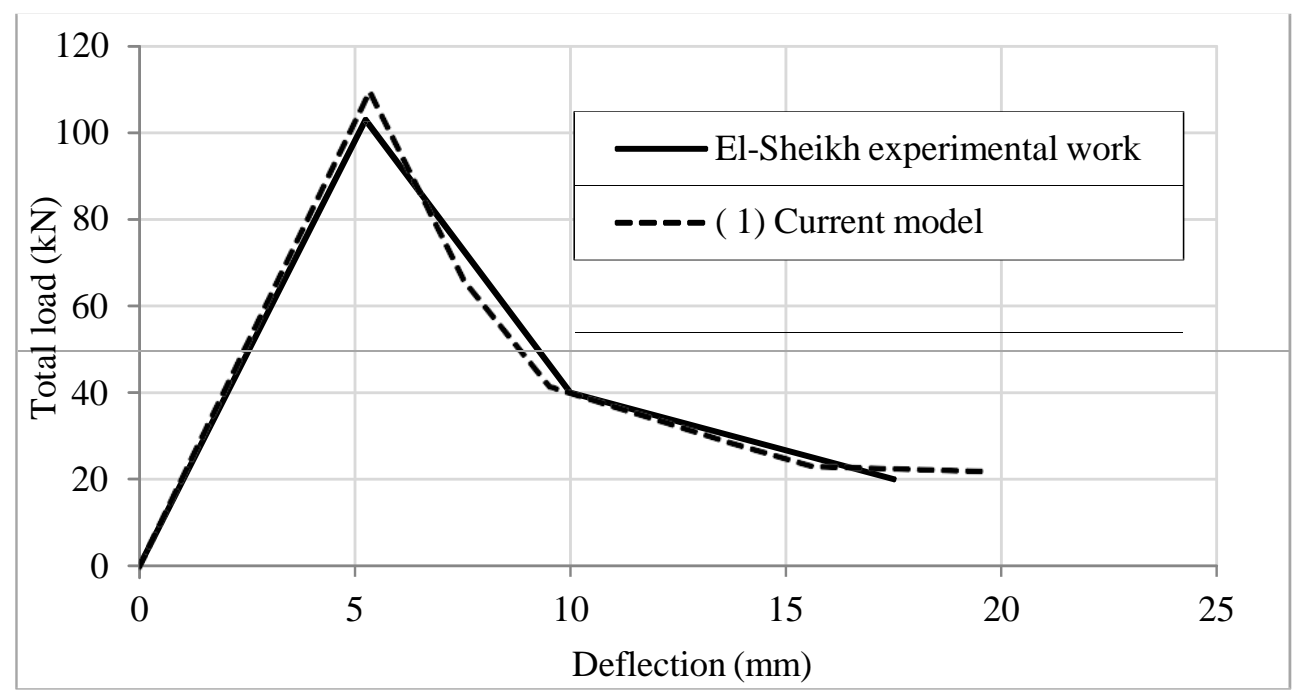

Fig. 12. Experimental and analytical total load - central vertical deflection curve of Truss (A) 

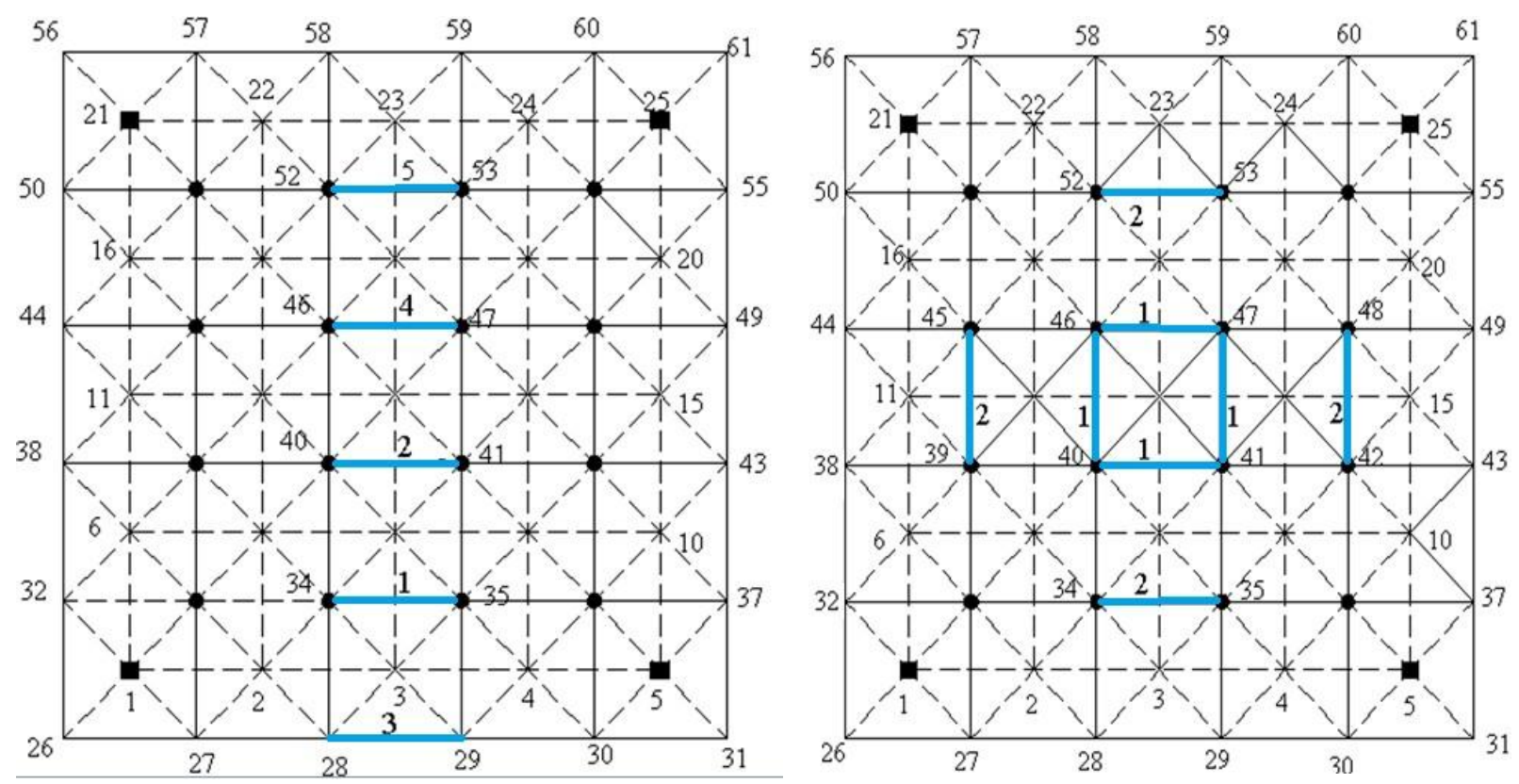

\section{Collapsed members}

a) Experimental work

b) Analytical analysis

Fig. 13. Collapsed members of the Truss (A)

The experimental results of Truss (B) indicated that the relationship between the applied external load and the deflections at central node was remained linear up the applied load of 210 $\mathrm{kN}$ as presented in Fig. 14. Also this figure indicates that the truss reached its maximum capacity at applied load of $276 \mathrm{kN}$ then the load was degraded. The experimental results indicated that truss (B) failed to carry the design factored load because of the occurring of the unpredicted buckling of the set of top members. The sequence of collapsed members due to experimental results of truss B was showed in Fig. 15. The relationship between the total load and center deflection from the current analysis using FE model\#1 shows a good agreement with the experimental results in the linear stage but it overestimates the applied load in the nonlinear stage as shown in Fig. 14. From the current finite element simulation results of Truss (B), the bottom members (8-13), (12-13), (14-13) and (18-13) are the first yielded members at applied load of $215 \mathrm{kN}$ then they followed by yielding of the members (9-14), (14-19), (7-12), (12-17), (8-9), (7$8),(17-18)$ and (18-19) at total applied load of $283 \mathrm{kN}$. Increasing the applied loads, top members (34-35), (52-53), (42-48) and (39-45) buckled at the total applied load of $285 \mathrm{kN}$. When the total applied load reaches the value of $330 \mathrm{kN}$, the members (40-46), (40-41), (41-47), (46-47), (1-33), (5-36), (25-54), and (21-51) buckled as shown in Fig. 15. 


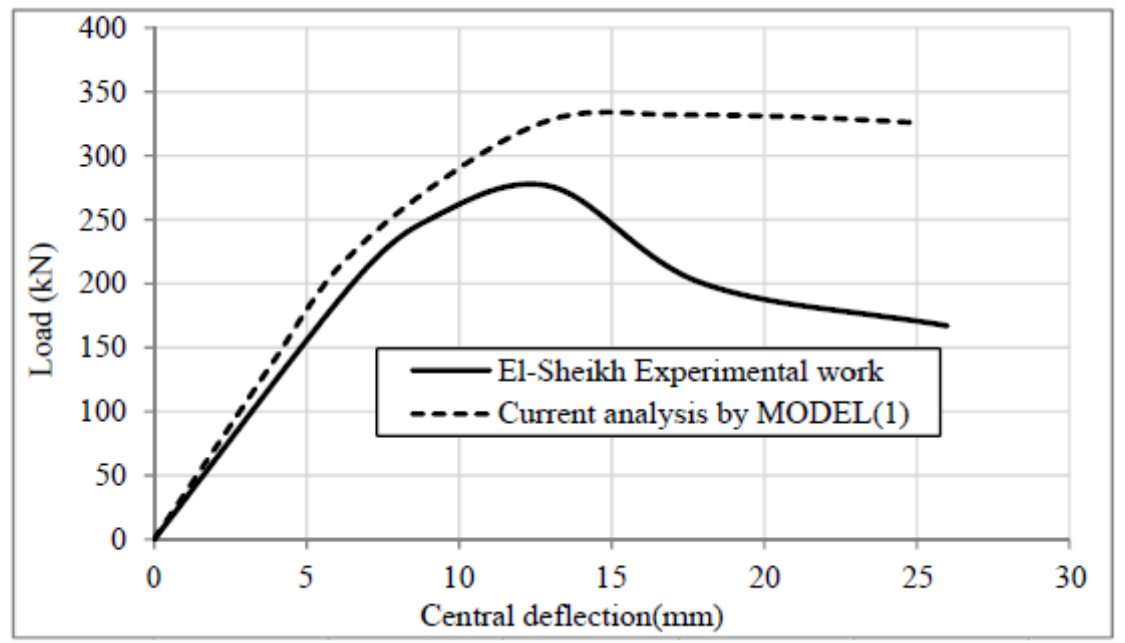

Fig. 14. The experimental and the current analytical load- deflection curves of Truss (B)

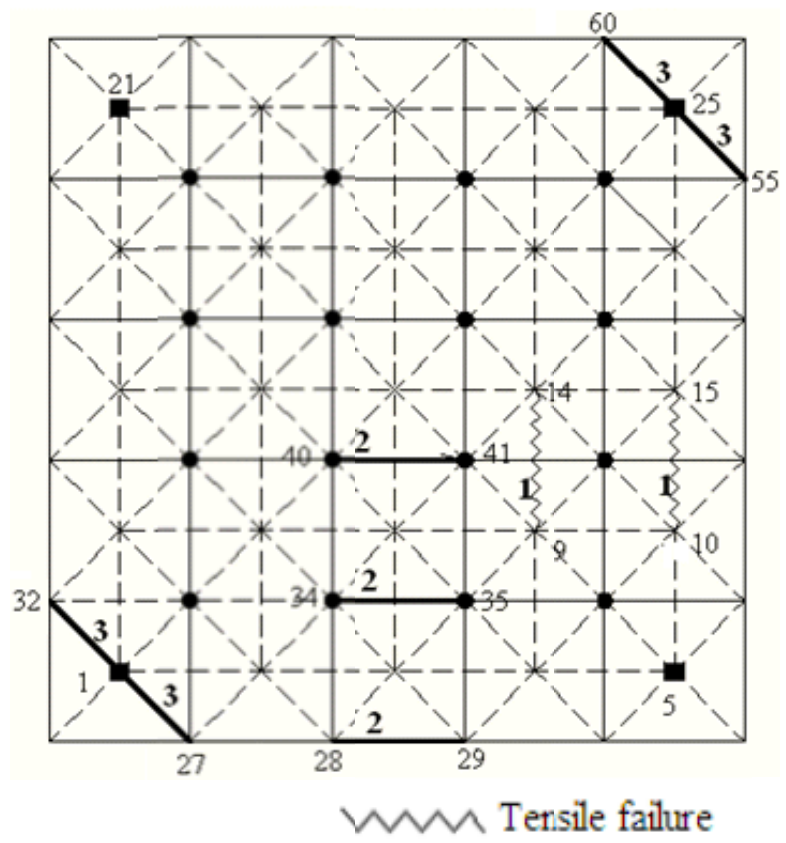

a) Experimental work

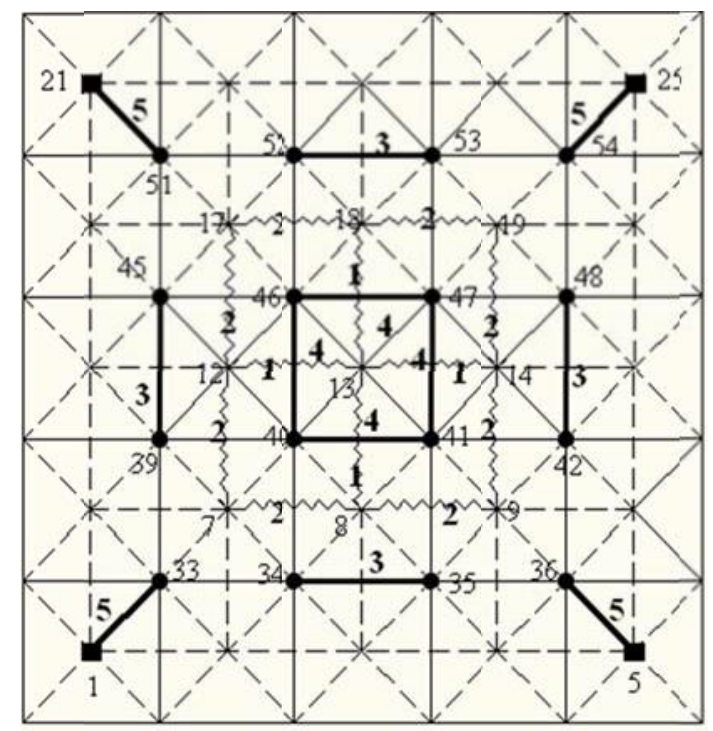

Buckling failure

b) Analytical analysis

Fig. 15. Sequence of the failed members of Truss (B)

Composite truss (Truss (C)) was simulated using Model\#2. The top concrete slap and the reinforcement were modeled in ANSYS program using Solid65 and Link8 elements; respectively. Each Solid65 element is defined by eight nodes as shown in Fig. 16 and each node has three degrees of freedom (translations in the nodal $\mathrm{x}, \mathrm{y}$, and $\mathrm{z}$ directions). This element has one solid material and up to three rebar materials in the three directions. The solid material is used to simulate the concrete while the rebar capability is used for simulating the reinforcements. This element has the ability of cracking (in the three orthogonal directions), crushing, plastic deformation, and cr ep (refer to ANSYS [28], Hoque [31], Singh [32] Shaheen et al. [33-35]) and Sangeetha and Senthil [36]. Steel bars were modeled by Link8 elements. Link8 is a uniaxial 
tension- compression element with three degrees of freedom at each node: translations in the nodal $\mathrm{x}, \mathrm{y}$, and $\mathrm{z}$ directions. Plasticity, creep, swelling, stress stiffening, and large deflection capabilities are included. The material of the concrete is defined by the compressive, tensile strength of concrete after 28 days, the modulus of elasticity and the multi-linear isotropic stressstrain curve. There is no any information about the reinforced concrete properties used in ELSheikh [25]. That is why the author employed the Egyptian Code for design and construction the reinforced concrete structures [37]. The modulus of elasticity of concrete $\left(\mathrm{E}_{\mathrm{c}}\right)$ can be calculated from Equation 1 by considering the compressive strength of concrete after 28 days $\left(\mathrm{F}_{\mathrm{cu}}\right.$ was considered as $20.0 \mathrm{E}+3 \mathrm{kN} / \mathrm{m}^{2}$ ). The multi-linear isotropic stress-strain curve for the concrete can be computed by Equation 2 . Where, $\mathrm{f}$ is stress at any strain $(\varepsilon)$ and $\varepsilon_{0}$ is the strain at the ultimate compressive strength at 28 days and can be found from Equation 3. The stressstrain curve for the reinforced concrete is presented in Fig. 17. The steel was considered as mild steel and was defined by the yield stress and the modulus of elasticity. The material properties of the concrete and the reinforcement were taken similar to the ordinary concrete and the mild steel; respectively. Displacement - control technique was used to simulate the applied load by ANSYS program.

$$
\begin{aligned}
& E_{c}=139140.22 \sqrt{F_{c u}} \\
& f=\frac{E_{c}}{1+\left(\varepsilon^{2} \varepsilon_{0}\right)^{2}} \\
& \varepsilon_{0}=\frac{2 F_{c u}}{E_{c}}
\end{aligned}
$$

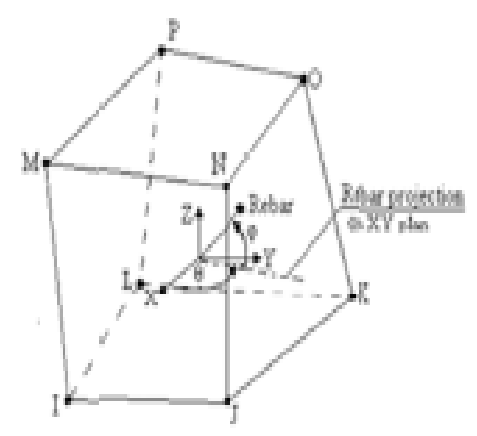

Fig. 16. Solid65 element

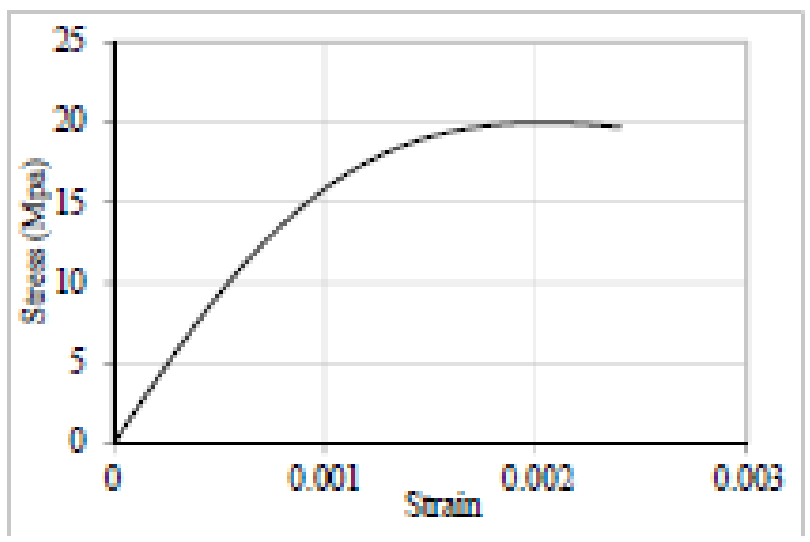

Fig. 17. Concrete stress-strain curve

Fig. 18 shows the relationship between the total load and the central deflection of Truss (C) as obtained from the experimental test and the analytical analysis model by El-Sheikh and the current analysis. From this figure, it can be seen a good agreement between El-Sheikh's results and the current analysis with a slight difference in the linear stage but both analytical analyses overestimates the applied load in nonlinear stage by about $15 \%$. The experimental test shows that 
bottom member (10-15) is the first yielded member at total applied load of $200 \mathrm{kN}$. Increasing the applied load, all bottom members reached to its yield at total applied load of $340 \mathrm{kN}$. Current analysis using Model\#2 indicated that the bottom members (8-13), (13-12), (13-14) and (13-18) are the first yielded members. Fig. 19 shows the total load and the collapsed members from the experimental work and the current analysis.

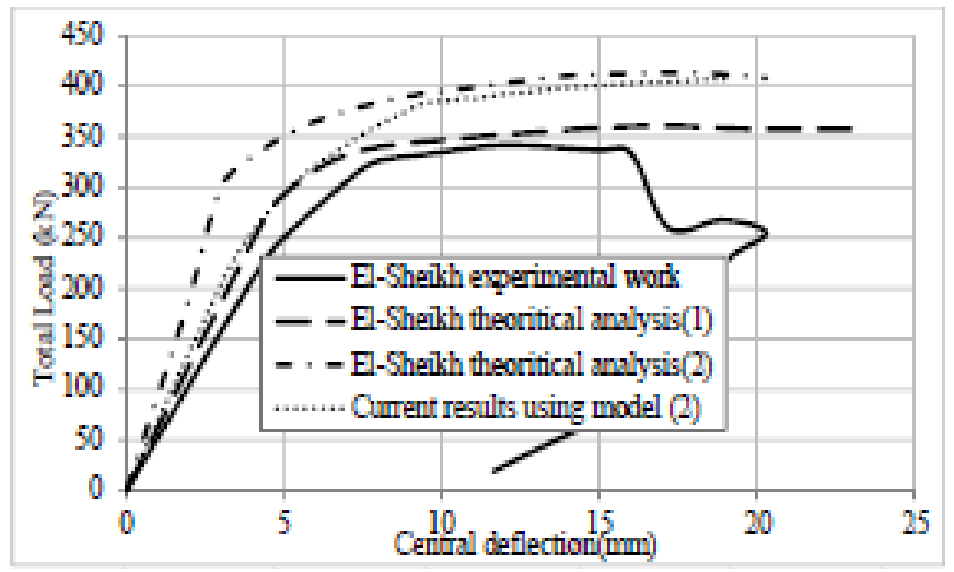

Fig. 18. Load- deflection curves of Truss (C)

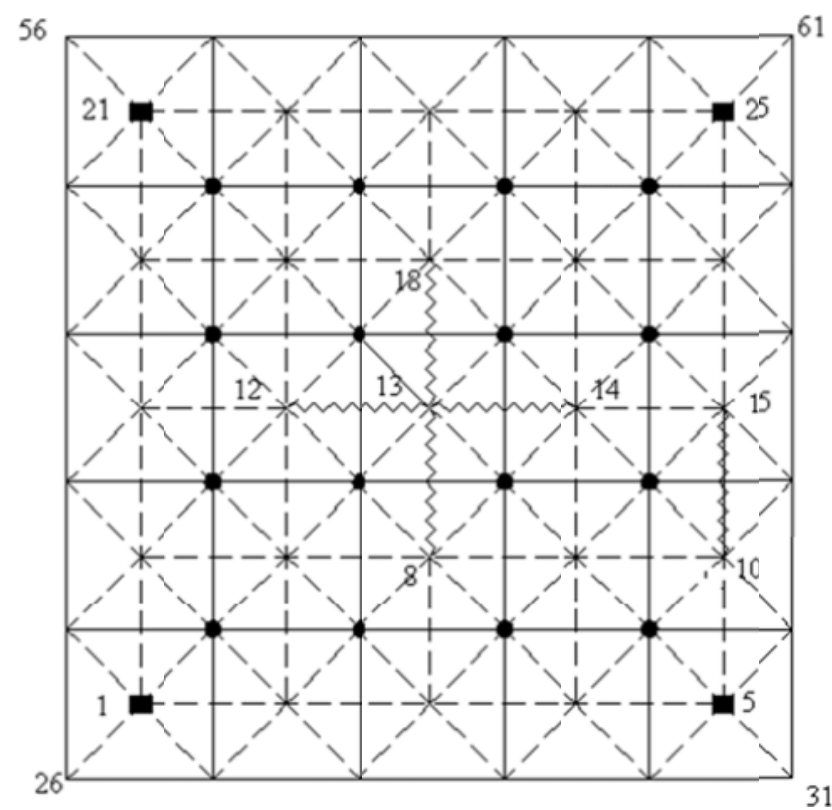

Fist yielding members from the current anlalysis

First yielding members from El-Shiekh experimental work

Fig. 19. Sequence of the failed members of Truss (C) 


\subsection{Studied Space Truss (4)}

Another experimental and analytical example for composite space trusses were made by Eltaly [21]. This study aimed to study the effect of top ferrocement slab on the non-linear behavior of the space trusses. Ferrocement is a highly versatile form of reinforced concrete commonly constructed of hydraulic cement mortar reinforced with wire mesh which possesses unique qualities of strength and serviceability. Ferrocement reinforcement is a wide variety of metallic reinforcing mesh materials; woven wire mesh, welded wire mesh and expanded metal mesh or non-metallic reinforcing mesh; glass fiber mesh and polyethylene mesh. Ferrocement concrete is characterized by low cost, weather-resistance, lightweight and particularly its versatility comparing to the rein orced concrete. It has been used in a wide range of applications, includin aqueducts, boats, buildings, bus shelters, bridge decks, food and water storage containers, irrigation structures, retaining walls, sculptures, roofing and traffic-caution signboards [33-35].

Eltaly [21] truss has $2850 \times 2850 \mathrm{~mm}$ overall dimensions and $500 \mathrm{~mm}$ depth in a square on square form. It was supported on the four bottom corners, and loaded at the upper central point (see Fig. 20). All the individual members formed the truss were fabricated from steel tubes with constant cross section (25.7 $\mathrm{mm}$ outer diameter and $1.2 \mathrm{~mm}$ wall thickness). The members were connected at the joints by using Triodetic system connection. The truss was covered by top ferrocement slab $\mathrm{w}$ th overall dimensions of $1975 \times 1975 \mathrm{~mm}$ and $35 \mathrm{~mm}$ thickness. The individual members and the ferrocement components slab were tested to determine their characteristics to be used in the analytical analysis. Fig. 21 shows the behavior of the individual members from tensile and compression test. From tensile test, modulus of elasticity, yield stress and ultimate strength were considered $2150 \mathrm{GPa}, 380 \mathrm{Mpa}$ and $525 \mathrm{Mpa}$; respectively. The component properties of the ferrocement slab are shown Fig. 21. In the current FE model, Top ferrocement slab wa modeled using Solid65 and Link8 elements.
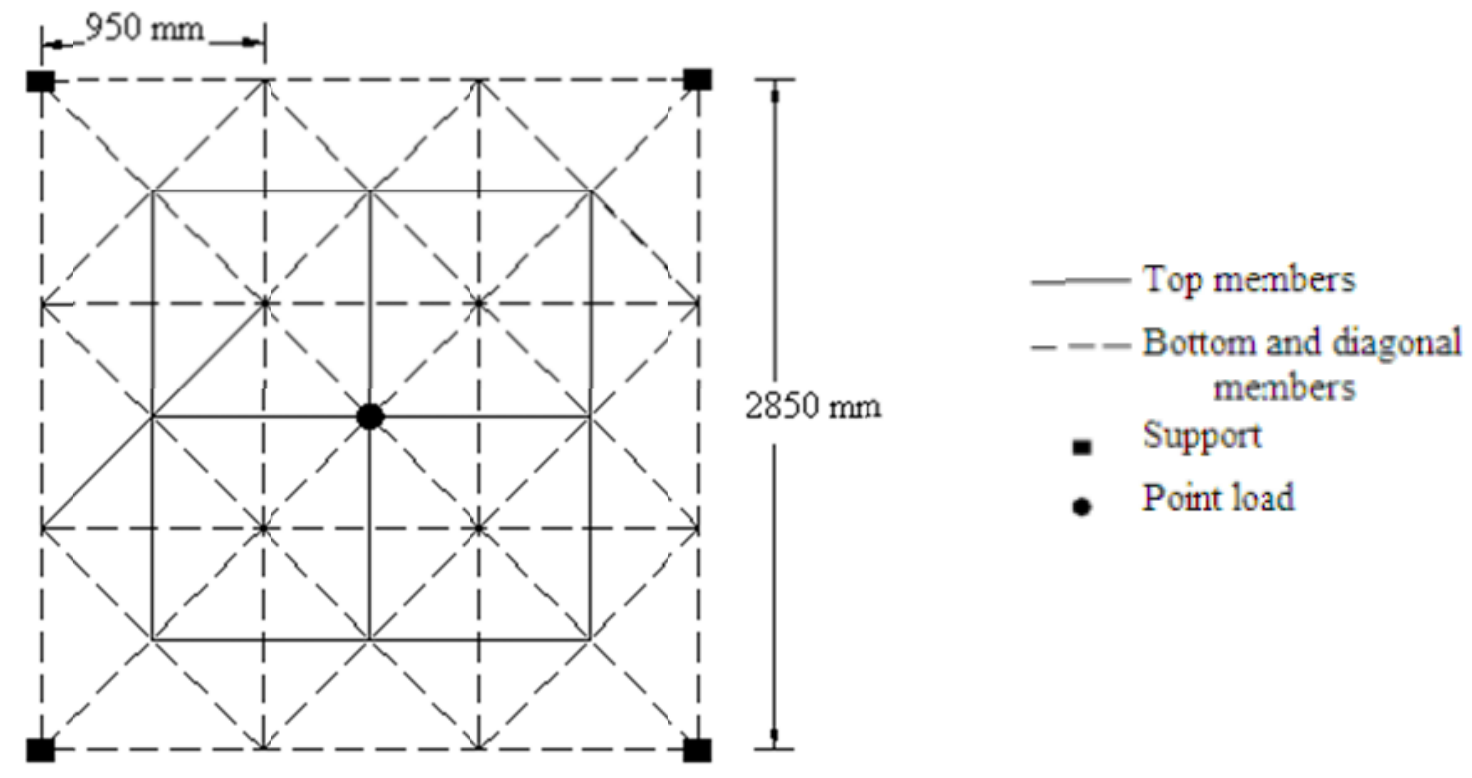

Fig. 20. General layout of the space truss with ferrocement slab 


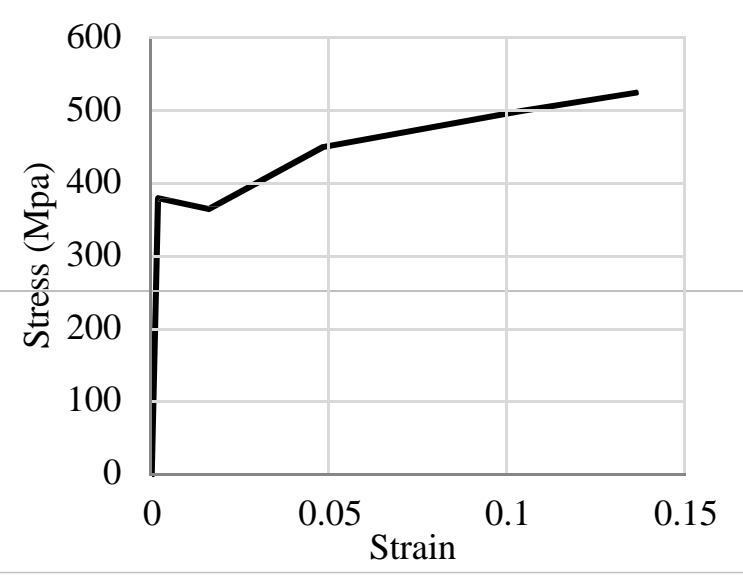

a) Under tensile test

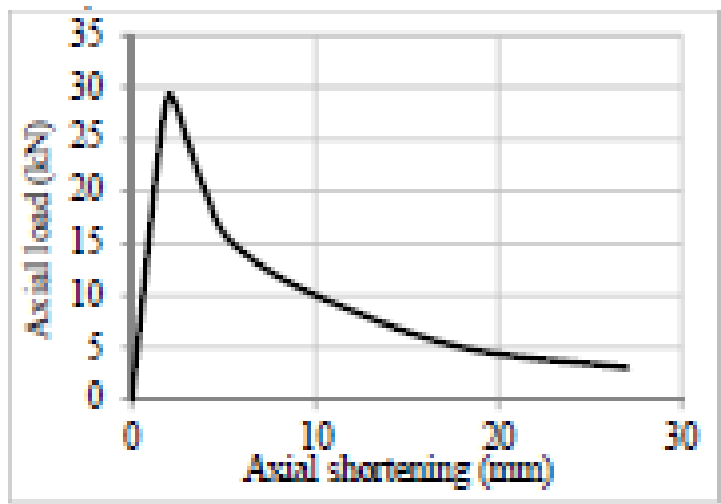

c) Diagonal members under compression test

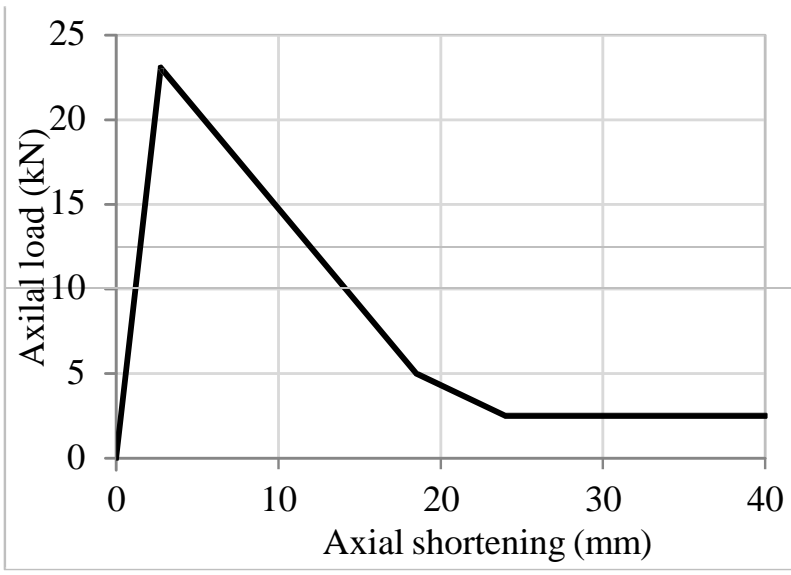

b) Chord members under compression test

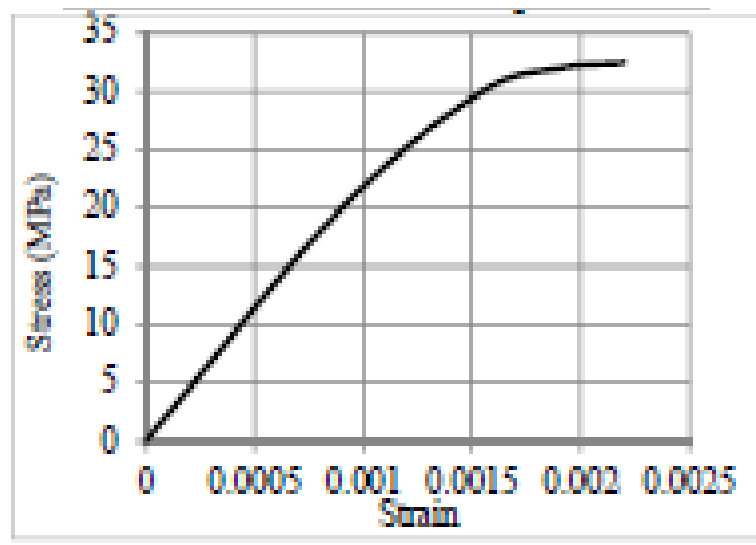

d) Mortar stress-strain curve

Fig. 21. Behavior of materials used in studied truss (4)

The results created by Eltaly [21] indicated that the relationship between the applied load and the central deflection remained linear until the applied load of $75 \mathrm{kN}$ with corresponding central deflection $3.5 \mathrm{~mm}$. Increasing applied load, the relationship stared to be nonlinear until the failure at the central deflection $4.8 \mathrm{~mm}$. Then the applied load decreased to $40 \mathrm{kN}$ and remained constant with increasing in the deflection as shown in Fig. 22. The results from the current analysis agree in the load - central deflection curve with the experimental results created by Elatly [21] as shown in Fig. 22. The experimental results indicated that the first collapse occurred at load of $75 \mathrm{kN}$ in the bottom member (2-3) at the connection number (2), then the truss is completely failed. Elatly [21] indicated that the failure of the connection is not expected because the analytical analysis indicated that the member (2-3) is a tension member and carry a small force in comparison with the other tensile members in the tested truss. Collapse of member (2-3) at the connection is due to a defect in the weld that was used in assembling process of the connection. The bottom member (6-7) reached its yielding at $4.8 \mathrm{~mm}$ central deflection (see Fig. 22). Un-symmetrically cracks occurred in the top ferrocement slab due to the failure of the connection of the truss where the part of the slab above the failed connection was cracked and the other remained without cracks. The view of the collapse of the tested truss is indicated in Fig. 23. In the current analysis, four central diagonal members are first members started to buckle at the applied load of $77 \mathrm{kN}$ then followed by buckling four diagonal corner members as seen in Fig. 24. The discrepancy between the experimental and the analytical results in the sequence of the failed members are due to the unexpected failure in connection (2). Fig. 25 and Fig. 26 show 
the defo med shape and the cracks pattern in the top slab from the current analytical analysis; respectively

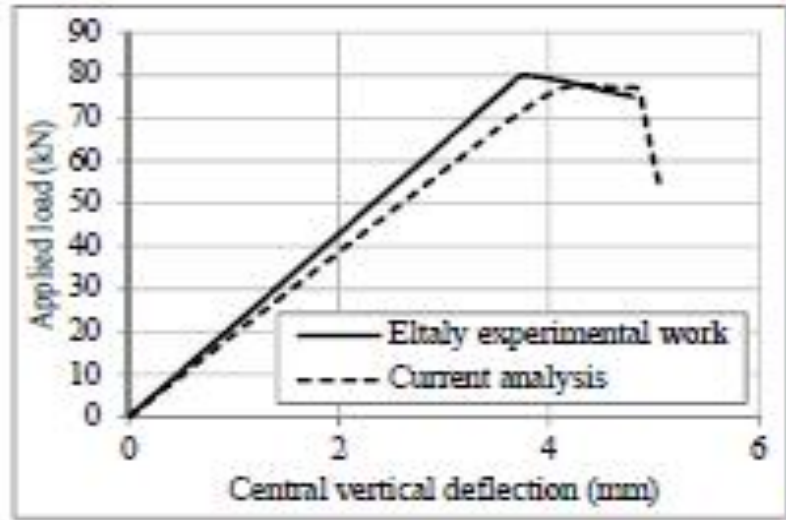

Fig. 22. Load-deflection curves of the studied truss (4)

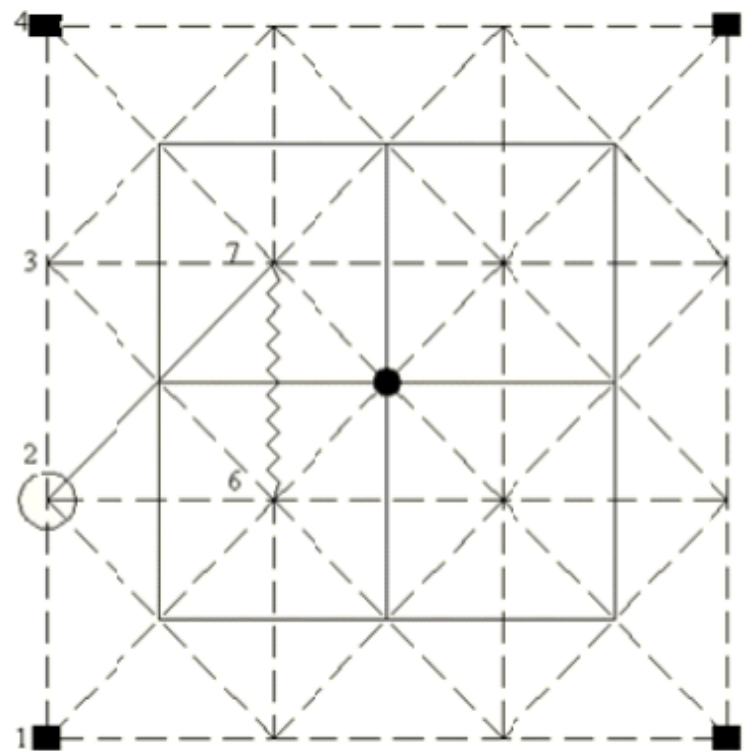

a) Experimental Work of Eltaly

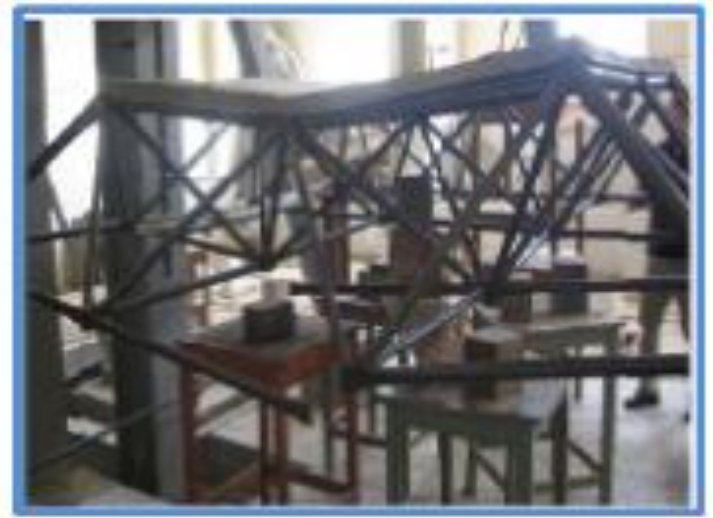

Fig. 23. Overall view of the collapsed tested truss (4)

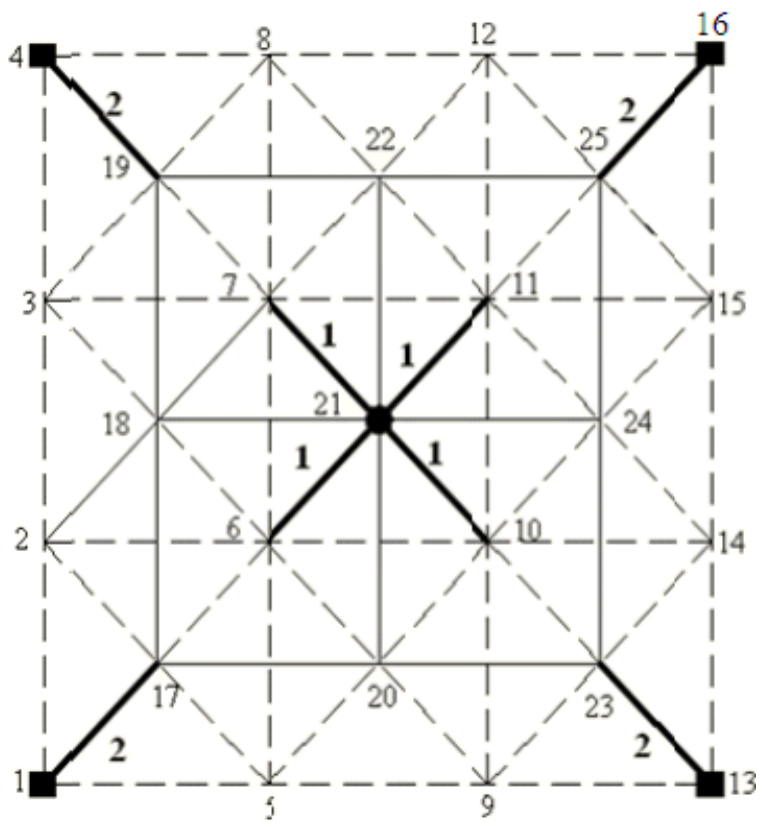

b) Current analytical analysis

Fig. 24. Collapsed members of studied truss (4) 


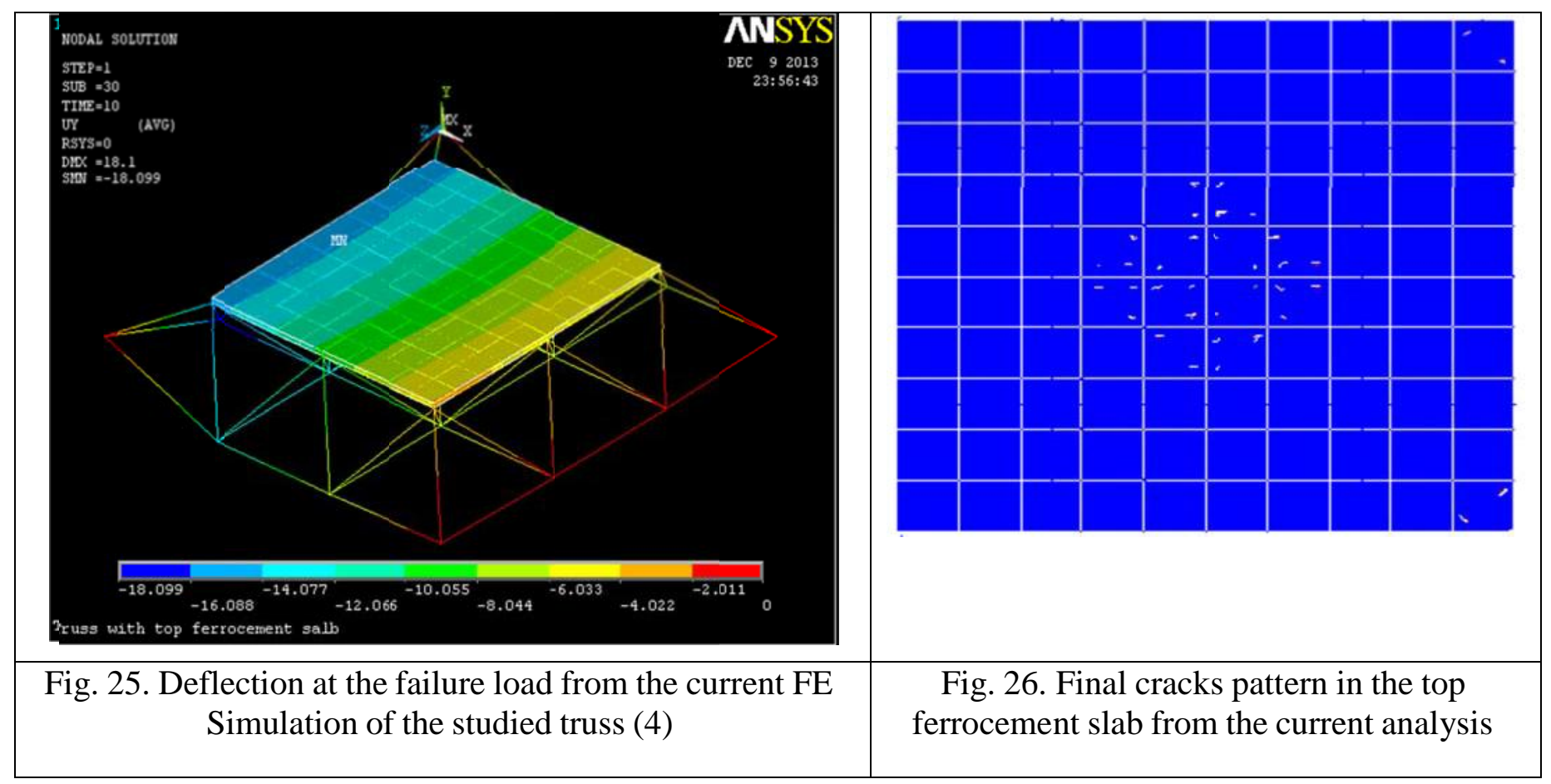

\section{Conclusions}

This research presented the static nonlinear analysis of the space trusses using the FE program ANSYS version 11. Two models were emp oyed in order to analyze the space trusses. The first model (Model\#1) simulates the non-composite space trusses and the second model (Model\#2) simulates the composite space trusses. The comparisons between the results of the current finite element models and the four previous published space trusses in order to verify the validity of the current models are presented. Comparisons between the results of the two models and the results of the four previous published space trusses conclude to:

1- For the first studied space truss, a good agreement between the experimental results and the current results with a slight difference does not exceed than $4 \%$ in the linear and the nonlinear stage. Sequence of collapsed members obtained from the current analytical analysis disagrees with the experimental results. The discrepancy in the sequence failure of the members between the experimental and the current analytical results is due to some factors which led to the discrepancy between the experimental and the analytical results created by Schmidt et al. [11].

2- For the second studied space truss, there is a very good agreement between the experimental results by Collin [30] and the current FE simulation with a slight difference in the linear stage that does not exceed than $6 \%$ but it is overestimated in the applied load in the nonlinear stage about $15 \%$. Also there is a good agreement between the experimental results by Collin [30] and the current FE simul tion in the sequence of the collapsed members.

3- For the third studied space truss, Three trusses (A, B non-composite trusses and C composite truss) created by Elshiekh [25] were analyzed by the two current models. The comparisons 
between the experimental and analytical results created by Elshiekh and the results of the current models indicated that:-

- According to the relationship between the total applied load and the central deflection, there is a good agreement in linear stage and the nonlinear stage for Truss (A). There is a large difference in the nonlinear stage for Truss (B) because of the occurring of the unpredicted buckling of the set of top members in the experimental results. Also the nonlinear stage for both analytical analyses is overestimated in the applied load in the nonlinear stage by $15 \%$.

- According to the sequence of the failed members, the analytical results differ with the experimental results for the three trusses. The imperfections, the unsymmetrical load system are the factors which predicted to make the discrepancy between the analytical and experimental results.

4- For the fourth studied space truss, there is a good agreement between the experimental results by Eltaly [21] and the current FE simulation in the relationship between the load and central deflection. The sequences of the collapsed members due to the experimental analysis disagree with the current result due to the unpredicted failure in connection (2) during the experimental test.

5- In general, we included that the numerical analysis created by the FE program ANSYS (v11) using Model\#1 and Model\#2 can predict the general collapse behavior of the space trusses.

\section{References}

1- Iffland, J., "Preliminary Planning of Steel Roof Space Trusses," Journal of Structural Division, ASCE, Vol. 108, No. ST11, pp. 2578-2591, November, 1982.

2- Iffland, J., "Preliminary Design of Space Trusses and Frames," Building Structural Design Handbook, Wiley-Interscience Publication, New York, 1987.

3- Lan, T. T., "Space Frame Structures," Structural Engineering Hand book, Chen Wai-Fah, Boca Raton: Crc Press Llc, 1999.

4- Ramaswamy, G. S., Eekhout, M., and Suresh, G. R., "Analysis, Design and Construction of Steel Space Frames," Thomas Telford, UK. 2002.

5- Chilton, J., "Space Grid Structures," Structural Hand Book, 90 Tottenham Court Road, London, England, 2000.

6- EL-Sheikh, A. I., "Development of a New Space Truss System," Journal of Constructional Steel Research, Vol. 37, No. 3, pp. 205-227, January, 1996.

7- Bakr, H., "Nonlinear Behavior of Composite Space Trusses under Earthquake Loads," Ms.c. Dissertation, Minoufia University, Egypt, 2014.

8- Elabd, M. "Effect of Composite Action on the Dynamic Behavior of space Structures," Ph. D. Dissertation, University of Dundee, UK, 2010.

9- Bakr, H., Eltaly, B., El-abd, M., and Kandil, K., "Finite Element Simulation of Space Trusses under Seismic Loads," $16^{\text {th }}$ International Conference on Aerospace Science \& Aviation Technology, ASAT-16, Military Technical College, Kobry Elkobbah, Cairo, Egypt. May 26 - 28, 2015.

10- Wolf, J. P., "Post Buckling Strength of Large Space Truss," Journal of Structural Division, ASCE, Vol. 99. No. ST7, pp. 1708-1712, July, 1973. 
11-Schmidt, L. C., Morgan, P, R., and Clarkson, J. A., "Space Trusses with Brittle-Type Strut Buckling," Journal of Structural Division, ASCE, Vol. 112, No. ST7, pp. 14791492, July, 1976.

12-Schmidt, L. C., and Gregg, B. M., "A Method for Space Truss Analysis in the PostBuckling Range," International Journal for Numerical Method in Engineering, Vol. 15, No. 2, pp. 237-247, February, 1980.

13-Smith, E. A., "Space Truss Nonlinear Analysis," Journal of Structural Engineering, ASCE, Vol. 110, No. 4, pp. 688-705, April, 1984.

14-Smith, E. A., and Smith, G. D., "Collapse Analysis of Space Trusses", Proceeding of symposium on long Span Roof Structures, ASCE, Vol. 107, No. 6, pp. 585-601, October, 1981.

15-Supple, W. J., and Collins, I., "Limit State Analysis of Double Grids," International Analysis, Design and Construction of Double Layer Grids, Applied Science Publishers, pp. 93-117, London, 1981.

16- Blandford, G. E., "Progressive Failure Analysis of Inelastic Space Truss Structures," Journal of Computers and Structures, Vol. 58, No. 5, pp. 981-990, 1996.

17- Yang, Y., Yang, C., Chang, T., and Chang, P., "Effects of Member Buckling and Yielding on Ultimate Strengths of Space Trusses," Engineering Structures, Vol. 19, No. 2, pp. 179-191, 1997.

18- Greco, M., Gesualdo, F., Venturini, W., and Coda, H., "Nonlinear Positional Formulation for Space Truss Analysis," Journal of Finite Elements in Analysis and Design, Vol. 42, pp. 1079 -1086, June, 2006.

19- Aboul-Anen, B., Elshafey, A., El-Shami, M., and Kandil, K., "A Finite Element Model for Space Trusses," $13^{\text {th }}$ International Conference on Structural and Geotechnical engineering, ICSGE2009, Cairo, Egypt, December. 27-29, 2009.

20- Aboul-Anen, B., Elshafey, A., El-Shami, M., and Kandil, K., "Nonlinear Analysis of Space Trusses," ASCE, Texas Section, 2009.

21-Eltaly, B., "Nonlinear Behavior of Composite Space Truss," Ph.D. Dissertation, Menoufia University, Egypt, 2010.

22-Schmidt, L. C., and Hanaor, A., "Force Limiting Devices in Space Trusses," Journal of Structural Division, ASCE, Vol. 150, No. ST5, pp. 939-951, May, 1979.

23-EL-Sheikh, A. I., "Effect of Force Limiting Devices on Behavior of Space Trusses," Engineering Structures, Vol. 21, pp. 34-44, 1999.

24-EL-Sheikh, A. I., "Experimental Study of Behavior of Composite Space Trusses," Journal of Structural Engineering, ASCE, Vol. 119, No. 3, pp. 747-766, March, 1993.

25- EL-Sheikh, A. I., "The Effect of Composite Action on the Behavior of Space Structures," Ph.D. Dissertation, Cambridge University, England, 1991.

26-El-Sheikh, A. I., and McConnel, R. E., "Experimental Study of Composite Space Trusses," Journal of Structural Engineering, ASCE, vol. 3, pp. 747-766, 1993.

27-EL-Sheikh, A. I., and Shaaban, H., "Experimental Study of Composite Space Trusses with Continuous Chords," Advances in Structural Engineering, Vol. 2, No. 3, pp 219232, United Kingdom, 1999.

28- ANSYS, "Help and Manual," $11^{\text {th }}$ Ed., ANSYS Inc, PA, USA, 2006.

29- SAP, program help and Manual, 2000.

30-Collins, I. M., "Collapse Analysis of Double-Layer Grids," Ph.D. Thesis, Surrey University, Guildford, England, 1981. 
31- Hoque, M., "3D Nonlinear Mixed Finite-element Analysis of RC Beams and Plates with and without FRP Reinforcement," M. Sc. Thesis, University of Manitoba, Winnipeg, Manitoba, Canada, 2006.

32-Singh, G., "Finite Element Analysis of Reinforced Concrete Shear Walls," M. Sc. Thesis, Deemed University, India, 2006.

33-Shaheen, Y. B. I., Eltaly, B. and Kameel, M., "Experimental and Analytical Investigation of Ferrocement Water Pipe," Journal of Civil Engineering and Construction Technolog, Vol. 4, No. 4, pp. 157-167, May, 2013.

34-Shaheen, Y. B. I., Eltaly, B. and Abul-Fataha, S., "Structural Performance of Ferrocement Beams Reinforced with Composite Materials," Structural Engineering and Mechanics, Vol. 50, No. 6 pp. 817-834, 2014.

35-Shaheen, Y. B. I., Eltaly, B. and Hanesh, A., "Experimental and FE Simulation of Ferrocement Domes Reinforced with Composite Materials," Concrete Research Letters, Vol. 5, No. 4, pp. 873-887, 2014.

36- Sangeetha P. and Senthil R., "A Study on Ultimate Behaviour of Composite Space Truss,” KSCE Journal of Civil Engineering, Vol. 21, No. 3, pp. 950-954, 2017.

37- Egyptian Code for Design and Construction Concrete Structures, No. 98, 2001. 